\title{
PREPARATION AND REFLECTIVE PROPERTIES OF SOME ALLOYS OF ALUMINUM WITH MAGNESIUM AND WITH ZINC
}

By R. G. Waltenberg and W. W. Coblentz

CONTENTS

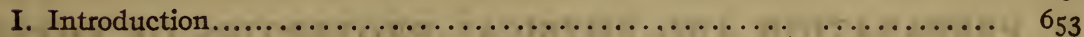

II. Preparation and physical properties of these alloys.................... $6_{54}$

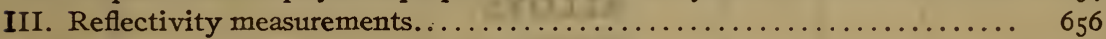

IV. Summary . . . . . . . . . . . . . . . . . . .

\section{INTRODUCTION}

During the past few years numerous requests for information regarding metals of high reflectivity have been received by this Bureau. A particularly urgent request was received for an alloy with high reflecting power throughout the spectrum. As some of the alloys of aluminum and magnesium give exceptional reflection in the ultra-violet it was thought desirable to make an investigation of the reflectivity of various alloys of these two metals.

L. Mach and V. Schumann ${ }^{1}$ gave an account of the preparation of aluminum-magnesium alloys of various compositions with remarks on their optical properties. Hagen and Rubens ${ }^{2}$ determined the reflectivity, in the ultra-violet, visible, and infra-red spectrum, of an alloy containing 69 per cent aluminum and $3 \mathrm{I}$ per cent magnesium, and it was shown to have an exceptionally high reflection in the ultra-violet. This alloy is known as Mach's magnalium.

An alloy for mirrors should be homogenous and uniform. It would not be expected that an alloy whose structure was made up of two or more constitutents would have a higher reflectivity than either of its structural constitutents, so that in a series of alloys of two or more metals we would expect the maximum or minimum reflection for any given wave length to occur for the composition at which a stable compound is formed, or in a range

\footnotetext{
1 Mach and Schumann, Sitzunber., Wien Akad., 108 A, p. 135; 1899.

2 Hagen and Rubens, Ann. d. Phys., 8, p. 16; 1902.
} 
in which the metals form a solid solution. Aluminum and magnesium form solid solutions only at low percentages of either metal, but they form a compound, $\mathrm{Al}_{3} \mathrm{Mg}_{4}$, containing 46 per cent aluminum and 54 per cent magnesium, ${ }^{3}$ and our efforts were confined largely to the preparation of mirrors of this compound.

Aluminum and zinc form a compound, ${ }^{4} \mathrm{Al}_{2} \mathrm{Zn}_{3}$, containing 78.3 per cent zinc and 21.7 per cent aluminum, and as both of these metals have rather high reflecting powers, a specimen of this compound was prepared and examined. The work of Rosenhain and Archbutt would indicate that, although this compound decomposes on slowly cooling, a chill-cast specimen would remain stable at room temperatures.

\section{PREPARATION AND PHYSICAL PROPERTIES OF THESE ALLOYS}

The specimens for reflectivity determinations were prepared from the purest materials available. The aluminum contained 0.15 per cent iron, 0.12 per cent silicon, and 0.02 per cent copper. The magnesium contained 0.08 per cent iron and 0.03 per cent copper. The zinc contained less than 0.05 per cent impurities.

Small castings about $25 \mathrm{~mm}$ diameter and weighing $100 \mathrm{~g}$ were made of alloys containing aluminum with 5 per cent magnesium, which is a duplex alloy consisting of a solid solution and the eutectic, with $3 \mathrm{I}$ per cent magnesium, which is the eutectic of the solid solution and the compound, and with 54 per cent magnesium, which is the compound. A similar specimen of the aluminumzinc compound containing 78.3 per cent zinc was prepared.

The alloys were made by melting the aluminum in an Acheson graphite crucible, and adding the magnesium or zinc to the molten aluminum, care being taken to keep the temperature of the molten material below $750^{\circ} \mathrm{C}\left(1380^{\circ} \mathrm{F}\right)$. The alloys were cast in a large graphite mold. Since it was not possible to get sound castings of the aluminum-magnesium compound, 54 per cent magnesium, in this manner, the specimens of this alloy were remelted in a vacuum, and cooled slowly. The preparation of this compound was simplified by the fact that on stirring the molten material an excess of either aluminum or magnesium would oxidize and leave the compound. This was confirmed by an examination with the miscroscope.

3 Grube, Zeit. Anorg. Chem., 45, p. 225, 1915; Schirmeister, Metal u. Erz., 11, p. 522, 1914.

-W. Rosenhain and L. S. Archbutt, Constitution of Alloys of Aluminum and Zinc, Phil. Trans. Royal Soc., 211, p. 315; r911. 
Plates of the $\mathrm{Mg}_{4} \mathrm{Al}_{3}$ I 2 inches $(30 \mathrm{~cm})$ square and I inch $(2.5 \mathrm{~cm})$ thick were prepared by casting the alloy in an iron mold, placing this mold in a vacuum furnace, melting the $\mathrm{Al}_{3} \mathrm{Mg}_{4}$ in vacuo, and cooling slowly. It was found necessary to cool this compound very slowly in order to relieve stresses in the casting. Some of the specimens burst into fragments after removal from a chill mold.

The compound of aluminum with magnesium, $\mathrm{Mg}_{4} \mathrm{Al}_{3}$, is very hard and brittle, and its resistance to the action of dilute acids and alkalies is much greater than any other magnalium which has come under our observation. A specimen of this compound was placed in 0.5 per cent $\mathrm{NaOH}$ for 90 minutes. The surface was not dulled appreciably, and no action could be detected with the microscope.

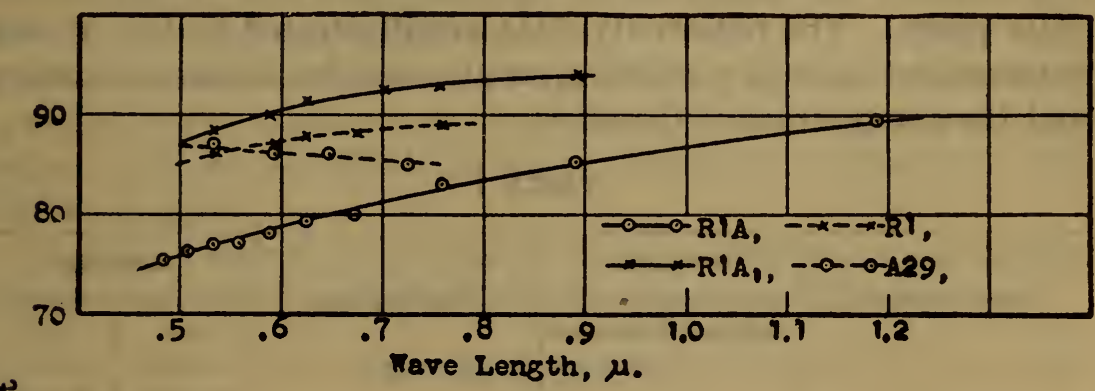

:

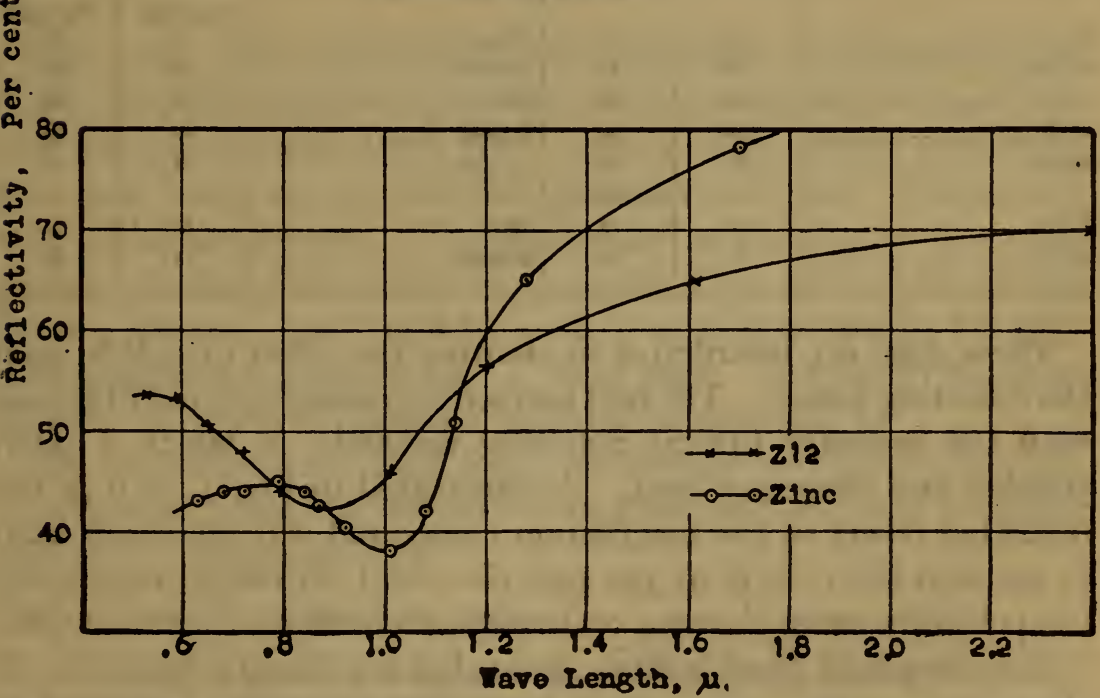

FIG. 1.-Reflecting power of zinc and of alloys of aluminum with zinc and with magnesium

On the other hand all the alloys made up, including the compound, seem to deteriorate on exposure to the air in the laboratory for a few weeks. The polished surfaces of the zinc-aluminum alloys 
tarnished in a few days. The magnesium-aluminum alloys seem to be more stable, but in view of the difficulties in preparing optically perfect surfaces, these alloys do not seem to be as suitable for mirrors as are nickel-steel and stellite. The reflectivities of the latter are lower, but the surfaces promise to be more permanent.

\section{REFLECTIVITY MEASUREMENTS}

The reflectivity measurements were made by means of a mirror spectrometer, a fluorite prism, and a vacuum thermopile described in previous publications. ${ }^{5}$ The reflecting power of the sample, which had a plane surface, was determined by comparison with a silver mirror; and also by a new method in which the silver reflecting surface was replaced by the hypotenuse face of a right-angled glass prism. The reflectivity data are illustrated in Fig. I, and summarized in Table $\mathrm{I}$, which gives also the identification numbers and the composition of the alloys.

TABLE 1

\begin{tabular}{|c|c|c|c|c|c|}
\hline \multirow{2}{*}{ Sample marked- } & \multicolumn{2}{|c|}{ Composition } & \multirow{2}{*}{ Kind of polish } & \multicolumn{2}{|c|}{ Reflection } \\
\hline & Aluminum & Magnesium & & $0.5 \mu$ & $0.7 \mu$ \\
\hline R-1-A... & 46 & 54 & Wax.. & $\begin{array}{l}\text { Per cent } \\
76\end{array}$ & $\begin{array}{l}\text { Per cent } \\
81\end{array}$ \\
\hline$R-1-A_{1} \ldots \ldots$ & 46 & 54 & Buffed........... & 89 & 92 \\
\hline R-1..... & 46 & 54 & Wax... & 86 & 88 \\
\hline$A-29 \ldots$. & 69 & 31 & Buffed..... & 87 & 86 \\
\hline$A-27 \ldots$. & 85 & $\begin{array}{c}15 \\
\text { Zinc. }\end{array}$ & .....do.... & 74 & 73 \\
\hline$z-12 \ldots \ldots \ldots \ldots \ldots$ & 22 & 78 & Wax. & 47 & 51 \\
\hline$z-12 \ldots \ldots$ & 22 & 78 & Buffed.. & 74 & 70 \\
\hline
\end{tabular}

These data are instructive in showing the effect of polish upon the reflecting power. The best surface for reflecting is not obtained with the ordinary optical polishing methods, in which a pitch polisher and rouge are used. As illustrated in Fig. I, at $0.7 \mu$ the reflecting power of the magnesium compound was increased from 8I per cent $(R-I-A)$ to 92 per cent $\left(R-I-A_{1}\right)$, by merely improving the polish by using alumina on broadcloth moistened with alcohol.

The sample of Mach's alloy, A-29, has a uniform reflectivity, of about 86 per cent, throughout the visible spectrum. This is in agreement with the observations of Hagen and Rubens (loc. cit.) who observed a uniform reflectivity of about 83 per cent.

\footnotetext{
. 5 W. W. Coblentz and W. B. Emerson, The Reflecting Power of Tungsten and Stellite, Scientific Paper No. 308, U.S. Bureau of Standards; $191 \%$
} 
The reflectivity curve of the alloy of aluminum and zinc, $\mathrm{Al}_{2} \mathrm{Zn}_{3}$ ( $\mathrm{Zn} \mathrm{I} 2$ in Fig. I) is unusual in that it has a wide minimum of reflectivity at $0.9 \mu$, beyond which point the reflectivity increases gradually to 93 per cent at $4 \mu$. This minimum is so novel that an examination of the reflectivity of pure zinc was made to determine whether there is a minimum in its reflectivity curve.

The bluish white color of a zinc mirror, and the unusually low reflectivity previously observed ${ }^{6}$ at $\mathrm{I} \mu$, indicate the possibility of a minimum of reflectivity in the region of $0.8 \mu$ to $0.9 \mu$. An examination of the reflectivity of the zinc mirror previously used, disclosed a sharp reflectivity minimum at $\mathrm{I} \mu$, as shown in Fig. $\mathrm{I}$. The surface of this mirror was not highly polished, which accounts for the low reflectivity throughout the spectrum. At $2 \mu$ the reflectivity was 85 per cent. $^{7}$

But few metals are known which have a minimum reflectivity ${ }^{8}$ in the infra-red, though, as is well known, copper and gold are excellent examples of metals having a reflectivity minimum in the visible spectrum.

As already stated, mirrors made of zinc-aluminum alloys tarnish rapidly, and hence are unsuitable for laboratory use.

\section{SUMMARY}

This paper gives the manner of preparation and determination of the spectral reflective properties of some alloys of aluminum with magnesium and with zinc. All of these alloys tarnish in time, and hence are not suitable for mirrors where permanency is of prime importance. The compound of aluminum and magnesium, $\mathrm{Al}_{3} \mathrm{Mg}_{4}$, deteriorates less rapidly than any of the other alloys examined, and could be used in apparatus where a highly reflecting mirror is desired for a short time. A reflectivity of 92 per cent at $0.7 \mu$ was obtained with this compound.

The zinc-aluminum alloy has a minimum reflectivity at $0.9 \mu$. An examination of the reflectivity of pure zinc disclosed a similar reflectivity minimum at $\mathrm{I} \mu$.

Washington, August 19, I9I9.

6 W. W. Coblentz, Radiometric Investigations of Infra-Red Absorption and Reflection Spectra, Scientific Paper No. 45, U. S. Bureau of Standards; 1907.

7 These data were obtained with the assistance of $\mathrm{H}$. Kahler, using a quartz prism which gives practically twice the dispersion of the fluorite prism used for obtaining the data on the alloy.

${ }^{8}$ See Coblentz and Emerson, loc. cit., for tungsten as a similar example. 
